\title{
The relationship between the dimensions of the internal auditory canal and the anomalies of the vestibulocochlear nerve
}

\author{
A.O. El Sadik, M.H. Shaaban \\ Anatomy and Embryology Department, Faculty of Medicine, Cairo University, Egypt \\ [Received: 8 May 2016; Accepted: 9 July 2016]
}

Background: Internal auditory canal (IAC) stenosis and vestibulocochlear nerve (VCN) abnormalities have been reported to be associated with sensorineural hearing loss. Previous studies classified the normal dimensions of the IAC and its anomalies with no consideration of the VCN. Other studies categorised the VCN development in only stenotic canals. In the present study, an anatomical classification of the normal dimensions of the IAC and its anomalies and their association with malformations of the VCN and its subdivisions were described.

Materials and methods: Retrospective review was undertaken for children ranged from 1 to 10 years. A total of 764 canals were investigated for pre-operative assessment of cochlear implantation. Other 100 canals of normal hearing ears were included as the control group. The maximum anteroposterior diameter, considered the width of the canal, was measured in axial plane and the length of the canal was identified in coronal plane. The canals were categorised normal: if they are from 3 to $8 \mathrm{~mm}$, patulous: if they are more than $8 \mathrm{~mm}$, stenotic: if they are less than $3 \mathrm{~mm}$ and atretic if absent, using multislice computed tomography. The VCN trunks and their subdivisions were investigated using magnetic resonance imaging.

Results: Internal auditory canals were found normal in $66 \%$ with a mean width: $5.27 \pm$ \pm 0.68 , patulous in $17 \%$ with a mean width $113 \%$ more than that of the control group $(p=0.000)$, stenotic in $13 \%$ with a mean width $73 \%$ less as compared to that of the control group $(p=0.000)$ and atretic in $4 \%$ of the experimental canals. The VCN trunks were found normal with well-developed subdivisions in $77.8 \%$ of the normal canals, $98.4 \%$ of the patulous canals, and $19.2 \%$ of the stenotic canals. The VCN trunks were normal with hypoplastic subdivisions in $11.3 \%$ of the normal canals, $1.6 \%$ in the patulous canals, and $61.6 \%$ in the stenotic canals with a mean width $52 \%$ less than that of the normal trunk with developed subdivisions. Hypoplastic VCN trunks with absent subdivisions were reported in $7.3 \%$ of the normal canals, $11.1 \%$ of the stenotic canals and in 3.2\% of the atretic canals. The VCN trunks were not found in 3.6\% of the normal canals, in $8.1 \%$ of the stenotic canals and in $96.8 \%$ of the atretic canals.

Conclusions: Internal auditory canal formation was dependent on the process of development and growth of the eighth cranial nerve and its subdivisions that greatly affected the completion of IAC canalisation. This paper could serve as a reference providing a quantitative classification of the relationship between the dimensions of the IAC and the development of the VCN trunk and its subdivisions. (Folia Morphol 2017; 76, 2: 178-185)

Key words: vestibulocochlear nerve, internal auditory canal, multislice computed tomography, magnetic resonance imaging

Address for correspondence: Assistant Professor A.O. El Sadik, Anatomy and Embryology Department, Faculty of Medicine, Cairo University, Egypt, e-mail: abeer.ouaida@kasralainy.edu.eg 


\section{INTRODUCTION}

Internal auditory canal (IAC) stenosis has been proved to be well correlated with congenital sensorineural hearing loss. One of the most common causes of this anomaly is lack of development of the vestibulocochlear nerve (VCN) $[11,16]$. Malformations of the IAC especially stenosis or atresia were suggested to be due to hypoplasia or aplasia of the VCN, respectively $[2,3,9,10]$. Other study suggested that stenosis of the IAC produces compression and damage of the VCN resulting in nerve dysfunction [19].

High resolution computerised tomography (CT) is considered a very sensitive method to investigate the precise dimensions of the IAC and the detection of its anomalies [14-16]. Recent technologies in magnetic resonance imaging (MRI) were proved to be more sensitive and specific for diagnosing soft tissue abnormalities in the IAC than the high resolution CT $[10,18,25]$. Moreover, thin-section T2-weigthed MRI in parasagittal planes was found to be the best to clarify the relationship of the facial and VCNs and their anomalies as they run laterally within the canal [20].

Previous studies classified the normal dimensions of the IAC and its malformations without evaluating the VCN $[6,15,21]$. Other studies classified the VCN development in only stenotic IAC with the exclusion of normal or enlarged canals [4]. Moreover, few studies have measured the dimensions of the IAC in children, as most of the studies were done on adults $[6,24]$ or on a very wide range of age; from 1 to 92 years [8] or from 1 to 72 years [5]. The aim of the present study was to provide an anatomical classification of the normal dimensions of the IAC and its anomalies in children aged from 1 to 10 years and their association with congenital malformations of the VCN and its subdivisions using the modern radiological techniques.

\section{MATERIALS AND METHODS}

\section{Participants}

Retrospective review was undertaken from Nile Scan CT and MRI divisions. The study was approved by the Research Ethics Committee, Faculty of Medicine, Cairo University. A total of 764 canals of 382 children were investigated for pre-operative assessment of cochlear implantation as a treatment of sensorineural hearing loss. Other 100 canals of normal hearing ears of 50 children who were referred to the centre to obtain cranial $\mathrm{CT}$ and MRI for various reasons, except hearing loss, were included in this study as the control group. These patients had no past medical history or clinical signs and symptoms related to ear diseases. The age of all children ranged from 1 to 10 years, born between January 2004 and December 2013. They were 220 males and 212 females. The medical charts of the patients were evaluated for age, sex, CT scans and MRI.

\section{Multislice CT (MSCT) imaging}

The tomography scanner Toshiba Asteon (MSCT-16 Detector) was used for obtaining the images. Axial cuts were $0.5 \mathrm{~mm}$ wide and taken at $0.5 \mathrm{~mm}$ intervals. Coronal images were reconstructed from the axial source images using multiplanar reconstruction (MPR) of every $0.5 \mathrm{~mm}$ wide section and $0.5 \mathrm{~mm}$ wide interval. The images were acquired by a high resolution algorithm with parameters; $120 \mathrm{Kvp}, 180 \mathrm{mAs}$, exposure time; $1.00 \mathrm{~s}$ and matrix size; $512 \times 512$.

The maximum anteroposterior diameter, which was considered the width of the canal, was measured in axial plane and the length of the canal, measured from its bottom to the centre of its orifice, was identified in coronal plane (Fig. 1). The maximum width of the IAC was found equal $8 \mathrm{~mm}$ and the minimum width was equal $3 \mathrm{~mm}$ in the control group. So the canals were categorised normal: if there width are from 3 to $8 \mathrm{~mm}$, patulous: if more than $8 \mathrm{~mm}$, stenotic: if less than $3 \mathrm{~mm}$ and atretic if absent [24].

\section{MRI protocol}

Magnetic resonance imaging was performed with a dedicated paediatric VCN protocol, on a 1.5 T scanner (Achiva Philips) 8-channel head coil. The protocol included axial and sagittal oblique T2-balance fast field echo (BFFE) weighted images. Parameters for the MR scanner (repetition time/echo time: 5.42-12.25 ms/ /2.42-5.9 ms, flip angle: $50-80^{\circ}$, field of view: 120-180 mm, matrix size: $512 \times 512$ ), with resultant near-isotropic voxel sizes ranging from 0.5 to $0.7 \mathrm{~mm}$ in length [6].

\section{Statistical analysis}

The data were studied using SPSS 20 statistical programme. The quantitative data were examined by Kolmogrov-Smirnov test for normality. Comparison of 

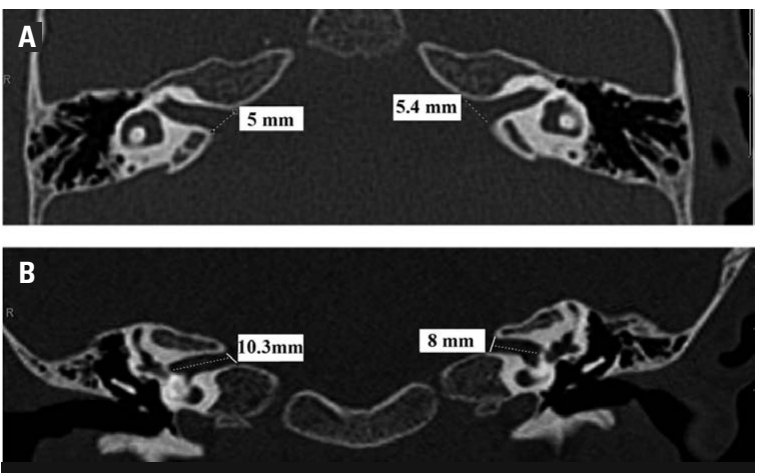

Figure 1. A. Axial multislice computed tomography (MSCT) section of the temporal bones showing bilateral normal internal auditory canal (IAC). The anteroposterior diameter of the right canal is $5 \mathrm{~mm}$ and the left canal is $5.4 \mathrm{~mm}$; $\mathbf{B}$. Coronal MSCT section of the same temporal bones showing the length of the IAC; $10.3 \mathrm{~mm}$ on the right side and $8 \mathrm{~mm}$ on the left side.

width, length and nerve trunks among the studied groups were done using one way ANOVA test. Chi-square $\left(\chi^{2}\right)$ test was used to study the association between the studied groups and nerve trunks.

\section{RESULTS}

Based on MSCT measurements, IACs were found normal in $66 \%$ of the experimental cases with a mean width: $5.27 \pm 0.68$ and mean length: $7.00 \pm 0.97$

Table 1. Mean \pm standard deviation (SD) of the width and length of the internal auditory canal in the different studied groups

\begin{tabular}{llcc}
\hline Cases & & Width & Length \\
\hline Control & Mean \pm SD & $5.44 \pm 1.02$ & $6.95 \pm 1.66$ \\
$100(100 \%)$ & Maximum & 8.00 & 11.00 \\
& Minimum & 3.00 & 3.00 \\
\hline Normal & Mean \pm SD & $5.27 \pm 0.68$ & $7.00 \pm 0.97$ \\
$505(66 \%)$ & Maximum & 8.00 & 11.00 \\
& Minimum & 3.00 & 3.00 \\
\hline Patulous & Mean \pm SD & $11.61 \pm 1.31$ & $8.46 \pm 0.64$ \\
$129(17 \%)$ & Maximum & 14.70 & 11.20 \\
& Minimum & 8.10 & 7.00 \\
\hline Stenotic & Mean \pm SD & $1.43 \pm 0.54$ & $10.46 \pm 0.75$ \\
$99(13 \%)$ & Maximum & 2.90 & 12.00 \\
& Minimum & 0.50 & 9.00 \\
\hline Atretic & Mean \pm SD & $0.00 \pm 0.00$ & $0.00 \pm 0.00$ \\
$31(4 \%)$ & Maximum & 0.00 & 0.00 \\
& Minimum & 0.00 & 0.00 \\
\hline
\end{tabular}
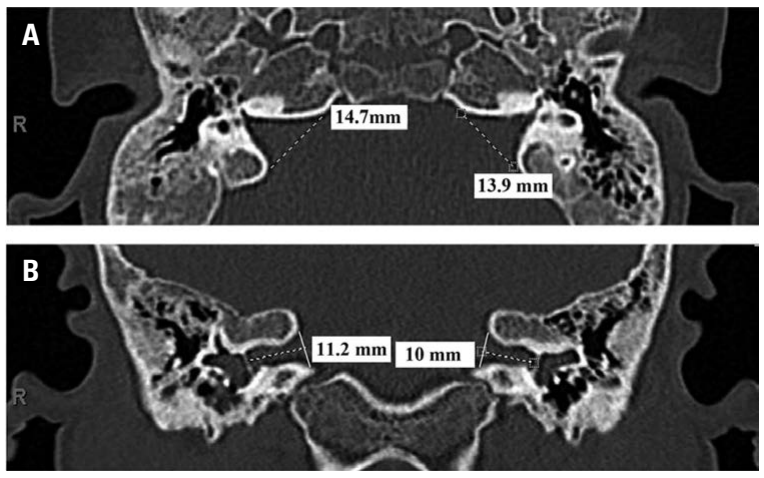

Figure 2. A. Axial multislice computed tomography (MSCT) section of the temporal bones showing bilateral patulous internal auditory canal (IAC). The anteroposterior diameter of the right canal is $14.7 \mathrm{~mm}$ and the left canal is $13.9 \mathrm{~mm}$; $\boldsymbol{B}$. Coronal MSCT section of the same temporal bones showing the length of the IAC; $11.2 \mathrm{~mm}$ on the right side and $10 \mathrm{~mm}$ on the left side.

(Fig. 1A, B, Table 1). Patulous canals were found in $17 \%$ of cases; with a mean width $113 \%$ more than that of the control group $(p=0.000)$ and mean length $21 \%$ more than that of the control group (Fig. 2A, B; Tables 1, 2). Stenosis was found in $13 \%$ of the canals; with a mean width $73 \%$ less as compared to that of the control group $(p=0.000)$ (Fig. $3 A, 4 A$ ) and mean length $50 \%$ more than that of the control group ( $p=0.000$ ) (Fig. 3B, 4B; Tables 1, 2). Lastly, atresia was found in $4 \%$ of the canals (Fig. 4A, B). However, gender distribution was not statistically significant $(p=0.07)$ within the different studied groups.

The association between the different IAC groups (control, normal, patulous, stenotic and atretic) and VCN trunks and subdivisions using $\chi^{2}$ test was highly significant $(p=0.000)$. VCN trunks were found normal with well-developed subdivisions (Fig. $5 \mathrm{~A}-\mathrm{C}$ ) in $77.8 \%$ of the normal canals, $98.4 \%$ of the patulous canals, $19.2 \%$ of the stenotic canals (Table 3 ).

The VCN trunks were normal with hypoplastic subdivisions (Fig. $6 \mathrm{~A}-\mathrm{C}$ ) in $11.3 \%$ of the normal canals, $1.6 \%$ in the patulous canals, $61.6 \%$ in the stenotic canals with a mean width $52 \%$ less than that of the normal trunk with developed subdivisions (Table 4). Hypoplastic VCN trunks with absent subdivisions (Fig. 7A-C, 8A, B) were reported in $7.3 \%$ of the normal canals, $11.1 \%$ of the stenotic canals and in $3.2 \%$ of the atretic canals. VCN trunks were not found (Fig. 8A, C) in $3.6 \%$ of the normal canals, in $8.1 \%$ of the stenotic canals and in $96.8 \%$ of the 
Table 2. Comparison of width and length of the internal auditory canal among the studied groups

\begin{tabular}{lllccc}
\hline Dependent variable & Cases $(\mathbf{I})$ & Cases $(\mathbf{J})$ & Mean difference: $\mathbf{l}-\mathbf{J}$ & $\mathbf{P}$ & Per cent of increase or decrease in relation to the control \\
\hline Width & Control & Normal & 0.17 & 0.593 & $3 \%$ \\
& & Patulous & $-6.18^{*}$ & 0.000 & $113 \%$ \\
& & $4.01^{*}$ & 0.000 & $73 \%$ \\
& & $5.44^{*}$ & 0.000 & \\
\hline Length & Atretic & -0.05 & 1.000 & $0.7 \%$ \\
& Control & Normal & $-1.51^{*}$ & 0.000 & $21 \%$ \\
& & Patulous & $-3.51^{*}$ & 0.000 & $50 \%$ \\
& Stenotic & $6.95^{*}$ & 0.000 & \\
\hline
\end{tabular}

${ }^{*}$ Statistically significant
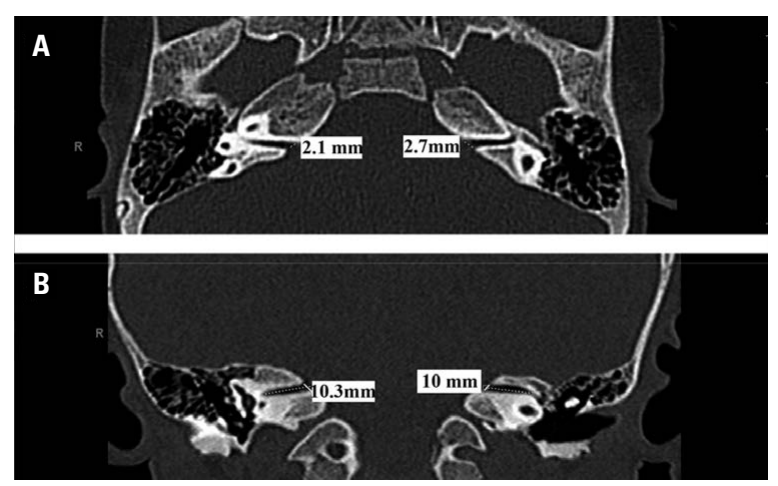

Figure 3. A. Axial multislice computed tomography (MSCT) section of the temporal bones showing bilateral stenotic internal auditory canal (IAC). The anteroposterior diameter of the right canal is $2.1 \mathrm{~mm}$ and the left canal is $2.7 \mathrm{~mm}$; B. Coronal MSCT section of the same temporal bones showing the length of the IAC; $10.3 \mathrm{~mm}$ on the right side and $10 \mathrm{~mm}$ on the left side.
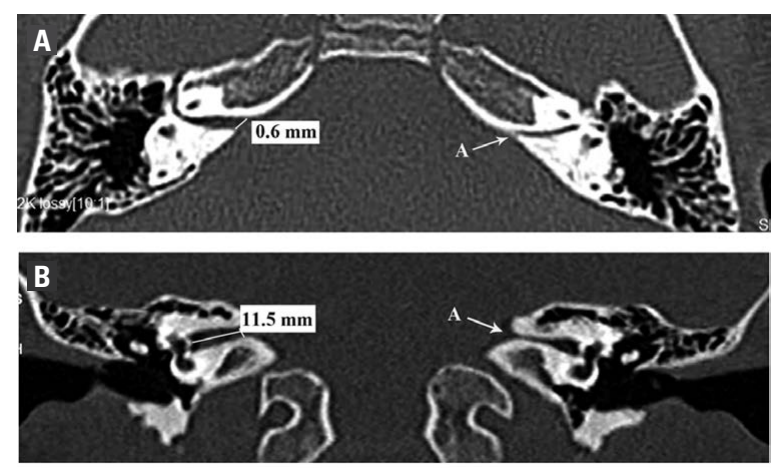

Figure 4. A. Axial multislice computed tomography (MSCT) section of the temporal bones showing right stenotic internal auditory canal (IAC). Its anteroposterior diameter is $0.6 \mathrm{~mm}$. The left canal is atretic (A); B. Coronal MSCT section of the same temporal bones showing the length of the left IAC; $11.5 \mathrm{~mm}$. atretic canals (Table 3). The mean width of the canal was $47 \%$ and $80 \%$ less in the hypoplastic trunk with no subdivisions and the aplastic trunk cases respectively as compared to that of the normal trunk with developed subdivisions. The mean length of the canal was $25 \%$ and $20 \%$ more in the normal trunk with hypoplastic subdivisions and hypoplastic trunk with no subdivisions cases respectively as compared to that of the normal trunk with developed subdivisions. However, it was 34\% less in the aplastic trunk than that of the normal trunk with developed subdivisions $(p=0.000)$ (Table 4).

\section{DISCUSSION}

Several studies examined the dimensions of the internal auditory canal using bony skulls [7], dissected cadavers [20] and radiographs [15]. In the present study, the IAC was considered patulous if its diameter was more than $8 \mathrm{~mm}$ and stenotic if less than $3 \mathrm{~mm}$. This classification is consistent with that of Thomsen et al. [24]. However, the authors investigated the IAC in individuals aged from 13 to 83 years. Other studies performed on children, like that of Huang et al. [10], Lang [12], Li et al. [13], and Marques et al. [15] classified the normal anteroposterior diameter of the IAC ranging from 3 to $7 \mathrm{~mm}$, from 4.64 to $5 \mathrm{~mm}$, from 2 to $8 \mathrm{~mm}$ and stenotic if less than $2 \mathrm{~mm}$, respectively. These variations in considering the normal dimensions could be resulted from the variability in the techniques used in measurements or due to the difference in age groups.

The shape and arrangement of the facial and vestibulocochlear nerves and their subdivisions, demonstrated in the control and normal groups of the 

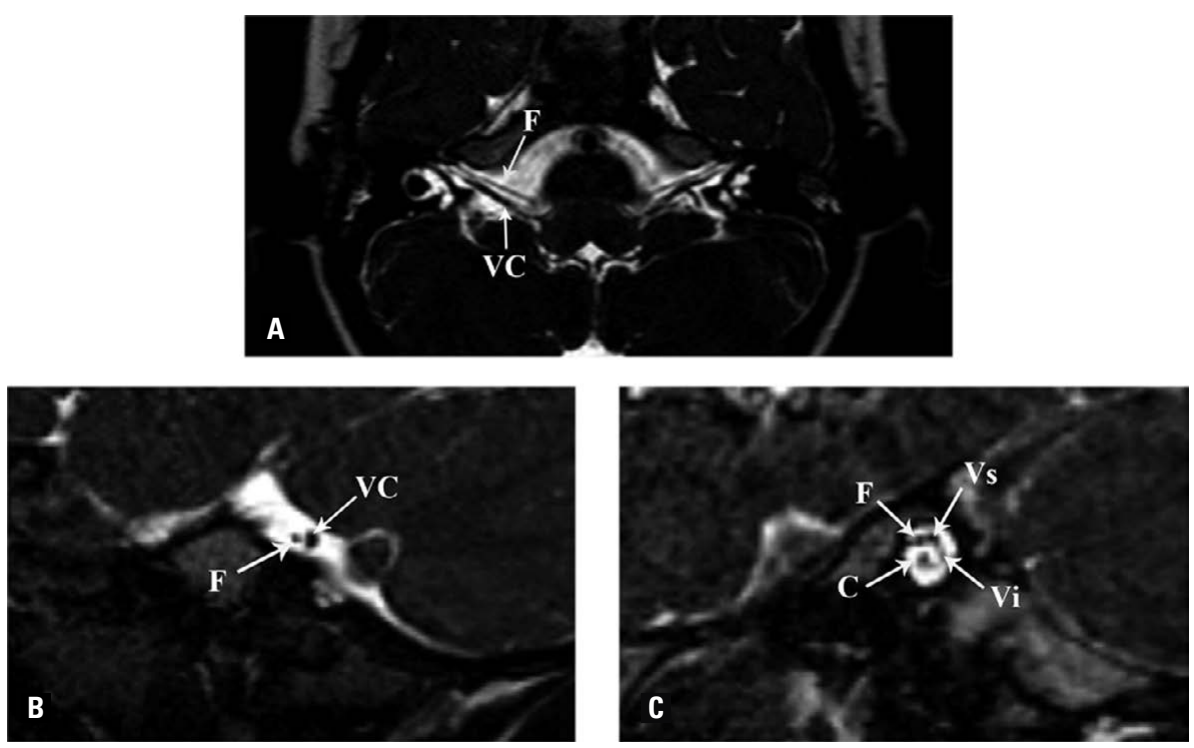

Figure 5. A. Axial magnetic resonance imaging balance fast field echo (MRI BFFE) T2-weighted section of the temporal bones of the patient in Figure 1 showing normal facial (F) and vestibulocochlear (VC) nerves on the right side; B, C. Sagittal oblique MRI BFFE T2-weighted section of the same temporal bone; B. In the cerebellopontine angle showing normal facial (F) nerve anterior to the main trunk of the vestibulocochlear (VC) nerve; C. Inside the internal auditory canal showing normal facial (F) nerve; anterosuperior to the subdivisions of the vestibulocochlear nerve. The cochlear (C) nerve is anteroinferior, superior division of the vestibular (Vs) nerve is posterosuperior and inferior division of the vestibular (Vi) nerve is posteroinferior.

Table 3. Association between the studied groups and vestibulocochlear nerve trunks and subdivisions using $\chi^{2}$ test

\begin{tabular}{|c|c|c|c|c|c|c|c|}
\hline \multirow[t]{2}{*}{ Cases } & & \multicolumn{4}{|c|}{ Nerve trunk } & \multirow[t]{2}{*}{ Total } & \multirow[t]{2}{*}{$\mathbf{P}$} \\
\hline & & $\begin{array}{l}\text { Normal trunk } \\
\text { with developed } \\
\text { subdivisions }\end{array}$ & $\begin{array}{l}\text { Normal trunk } \\
\text { with hypoplas- } \\
\text { tic subdivisions }\end{array}$ & $\begin{array}{l}\text { Hypoplastic } \\
\text { trunk with no } \\
\text { subdivisions }\end{array}$ & Aplastic trunk & & \\
\hline \multirow[t]{2}{*}{ Control } & Count & 100 & 0 & 0 & 0 & 100 & $0.000^{*}$ \\
\hline & $\%$ within cases & $100.0 \%$ & $0.0 \%$ & $0.0 \%$ & $0.0 \%$ & $100.0 \%$ & \\
\hline \multirow[t]{2}{*}{ Normal } & Count & 393 & 57 & 37 & 18 & 505 & \\
\hline & $\%$ within cases & $77.8 \%$ & $11.3 \%$ & $7.3 \%$ & $3.6 \%$ & $100.0 \%$ & \\
\hline \multirow[t]{2}{*}{ Patulous } & Count & 127 & 2 & 0 & 0 & 129 & \\
\hline & $\%$ within cases & $98.4 \%$ & $1.6 \%$ & $0.0 \%$ & $0.0 \%$ & $100.0 \%$ & \\
\hline \multirow[t]{2}{*}{ Stenotic } & Count & 19 & 61 & 11 & 8 & 99 & \\
\hline & $\%$ within cases & $19.2 \%$ & $61.6 \%$ & $11.1 \%$ & $8.1 \%$ & $100.0 \%$ & \\
\hline \multirow[t]{2}{*}{ Atretic } & Count & 0 & 0 & 1 & 30 & 31 & \\
\hline & $\%$ within cases & $0.0 \%$ & $0.0 \%$ & $3.2 \%$ & $96.8 \%$ & $100.0 \%$ & \\
\hline \multirow[t]{2}{*}{ Total } & Count & 639 & 120 & 49 & 56 & 864 & \\
\hline & $\%$ within cases & $74.0 \%$ & $13.9 \%$ & $5.7 \%$ & $6.5 \%$ & $100.0 \%$ & \\
\hline
\end{tabular}

*Statistically significant

present work using MRI protocol, were in agreement with the results described by several researchers $[1,17,20,22,23]$. Hypoplastic subdivisions of the VCN were found in $61.6 \%$ of the stenotic canals and aplastic nerve trunks were found in $96.8 \%$ of the atretic canals which were considered highly significant $(p=0.000)$. These resultsindicated that stenosis or atresia of the IAC could be explained as being secondary to hypolplasia or aplasia of the VCN as reported by the studies of Baek et al. [2], Giesemann et al. [9], and 

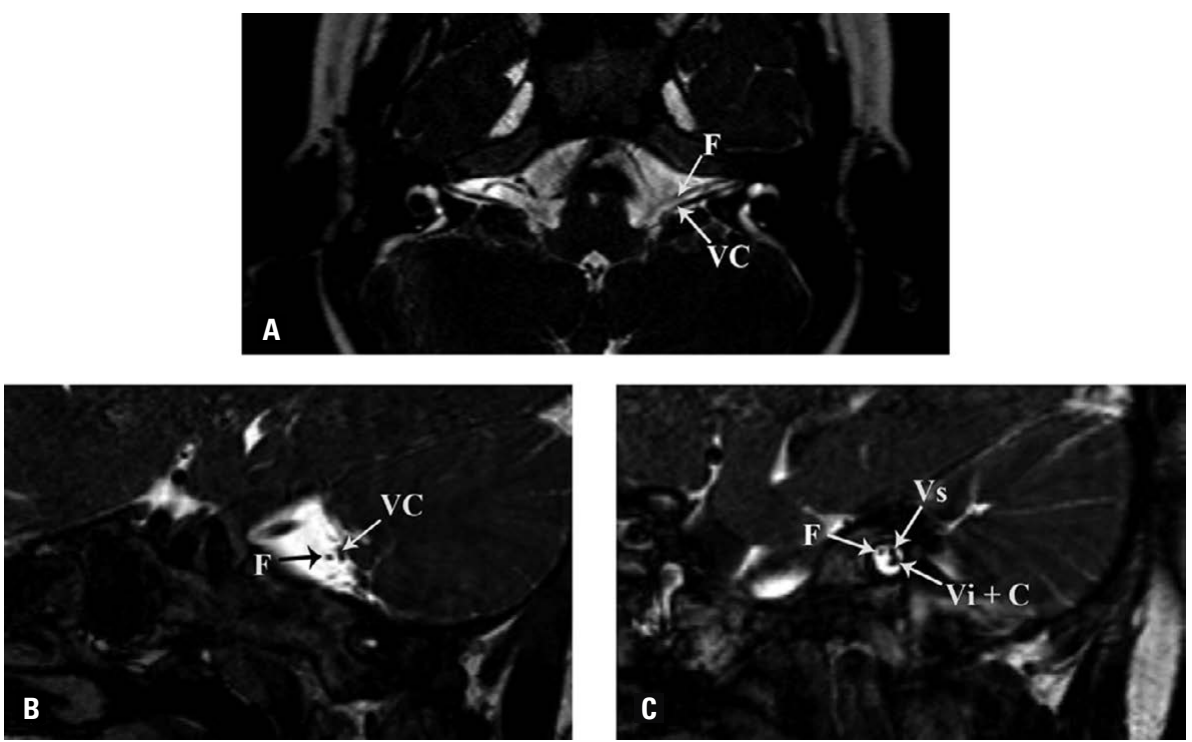

Figure 6. A. Axial magnetic resonance imaging balance fast field echo (MRI BFFE) T2-weighted section of the temporal bones of the patient in Figure 2 showing the facial (F) and vestibulocochlear (VC) nerves on the left side; B, C. Sagittal oblique MRI BFFE T2-weighted section of the same temporal bone; B. In the cerebellopontine angle showing the facial (F) nerve anterior to the main trunk of the vestibulocochlear (VC nerve; C. Inside the internal auditory canal showing the facial (F) nerve and hypoplastic subdivisions of the vestibulocochlear nerve; superior division of the vestibular (Vs), inferior division of the vestibular (Vi) and cochlear (C) nerves.

Table 4. Comparison of the nerve trunks and subdivisions among the different groups in relation to the width and length of the internal auditory canal

\begin{tabular}{|c|c|c|c|c|c|}
\hline $\begin{array}{l}\text { Dependent } \\
\text { variable }\end{array}$ & (I) Nerve & (J) Nerve & Mean difference: $\mathbf{I} J$ & $\mathbf{P}$ & $\begin{array}{l}\text { Per cent of increase } \\
\text { or decrease in relation } \\
\text { to the control }\end{array}$ \\
\hline \multirow[t]{3}{*}{ Width } & \multirow{3}{*}{$\begin{array}{l}\text { Normal trunk } \\
\text { with developed } \\
\text { subdivisions }\end{array}$} & $\begin{array}{l}\text { Normal trunk with } \\
\text { hypoplastic subdivisions }\end{array}$ & $3.49^{*}$ & 0.000 & $52 \%$ \\
\hline & & $\begin{array}{l}\text { Hypoplastic trunk with } \\
\text { no subdivisions }\end{array}$ & $3.17^{*}$ & 0.000 & $47 \%$ \\
\hline & & Aplastic trunk & $5.29 *$ & 0.000 & $80 \%$ \\
\hline \multirow[t]{3}{*}{ Length } & \multirow{3}{*}{$\begin{array}{l}\text { Normal trunk } \\
\text { with developed } \\
\text { subdivisions }\end{array}$} & $\begin{array}{l}\text { Normal trunk with } \\
\text { hypoplastic subdivisions }\end{array}$ & $-1.82^{*}$ & 0.000 & $25 \%$ \\
\hline & & $\begin{array}{l}\text { Hypoplastic trunk with } \\
\text { no subdivisions }\end{array}$ & $-1.43^{*}$ & 0.000 & $20 \%$ \\
\hline & & Aplastic trunk & $2.45^{*}$ & 0.000 & $34 \%$ \\
\hline
\end{tabular}

${ }^{*}$ Statistically significant

Huang et al. [10]. Moreover, the present study confirmed the relationship between the width and length of the canals and the development of the nerves and their subdivisions. The mean width of the canals was found to be $52 \%, 47 \%$ and $80 \%$ less with the normal nerve trunk with hypoplastic subdivisions, hypoplastic trunk with no subdivisions and aplastic nerve trunk respectively compared to that of the normal trunk and subdivisions, indicating a highly significant $(p=0.000)$ association between the small calibres of the
IAC and the congenital malformation of the VCN. Concerning these results, it has been suggested that IAC formation was dependent on the process of development and growth of the eighth cranial nerve and its subdivisions that greatly affected the completion of IAC canalisation.

\section{CONCLUSIONS}

Based on MSCT, IAC stenosis or atresia are highly indicative for MR examination of VCN trunk and its 

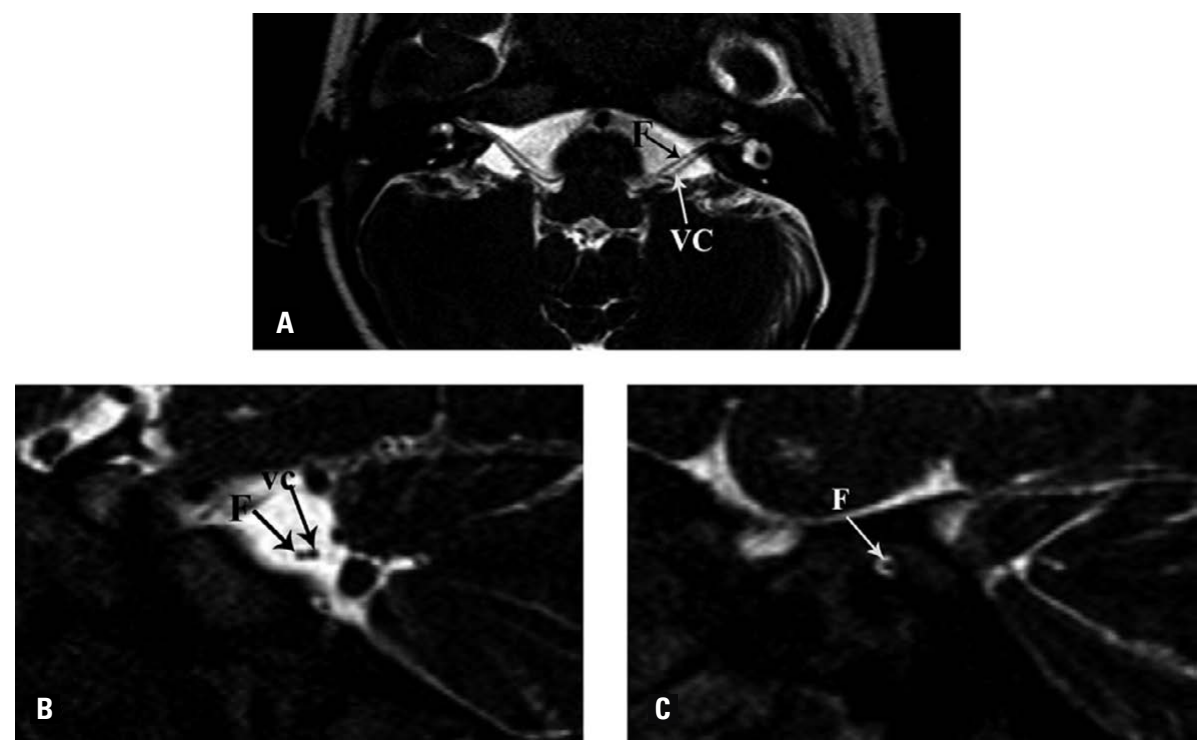

Figure 7. A. Axial magnetic resonance imaging balance fast field echo (MRI BFFE) T2-weighted section of the temporal bones of the patient in Figure 3 showing the facial (F) and vestibulocochlear (VC) nerves on the left side; B, C. Sagittal oblique MRI BFFE T2-weighted section of the same temporal bone; B. In the cerebellopontine angle showing the facial (F) nerve anterior to the hypoplastic main trunk of the vestibulocochlear (VC) nerve; C. Inside the internal auditory canal showing only the facial (F) nerve with absent subdivisions of the vestibulocochlear nerve.
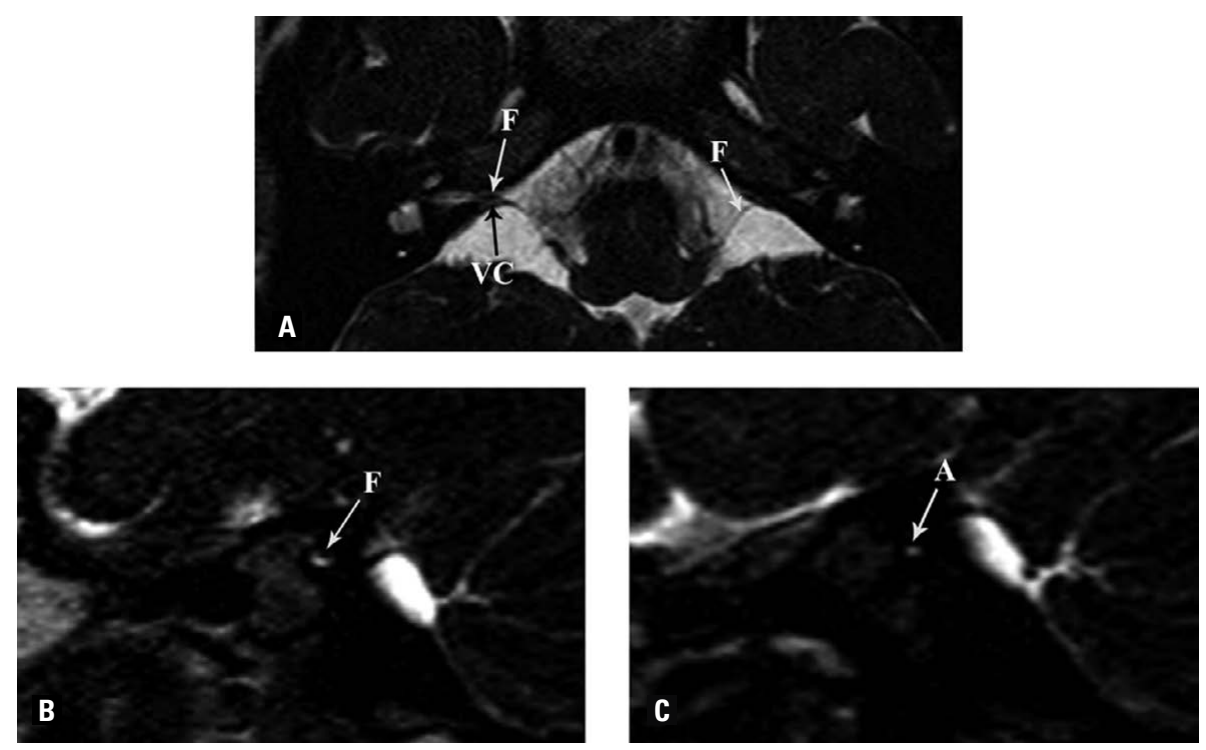

Figure 8. A. Axial magnetic resonance imaging balance fast field echo (MRI BFFE) T2-weighted section of the temporal bones of the patient in Figure 4 showing the facial (F) and vestibulocochlear (VC) nerves on the right side and only the facial (F) nerve on the left side; B, C. Sagittal oblique MRI BFFE T2-weighted section of the temporal bone inside the internal auditory canal; $B$. The right side shows only the facial (F) nerve with absent subdivisions of the vestibulocochlear nerve; C. The left side shows absent facial and vestibulocochlear nerves (A).

subdivisions as regarded greatly influencing the development of the canal. This paper could serve as a reference providing a quantitative classification of the relationship between the dimensions of the IAC and the development of the VCN trunk and its subdivisions.

\section{Acknowledgments}

The authors thank Professor Sherif Zaky for providing his inspiring assistance and critical comments and advices especially in the statistical work and classifications for calculations and validity of deductions. 


\section{REFERENCES}

1. Adunka OF, Roush PA, Teagle HFB, et al. Internal auditory canal morphology in children with cochlear nerve deficiency. Otol Neurotol. 2006; 27(6): 793-801, doi: 10.1097/01.mao.0000227895.34915.94, indexed in Pubmed: 16936566.

2. Baek SK, Chae SW, Jung HH. Congenital internal auditory canal stenosis. J Laryngol Otol. 2003; 117(10): 784-787, doi: 10.1258/002221503770716205, indexed in Pubmed: 14653919.

3. Casselman JW, Offeciers FE, Govaerts PJ, et al. Aplasia and hypoplasia of the vestibulocochlear nerve: diagnosis with MR imaging. Radiology. 1997; 202(3): 773-781, doi: 10.1148/radiology.202.3.9051033, indexed in Pubmed: 9051033.

4. Casselman JW, Offeciers EF, De Foer B, et al. CT and MR imaging of congential abnormalities of the inner ear and internal auditory canal. Eur J Radiol. 2001; 40(2): 94-104, indexed in Pubmed: 11704356.

5. Djalilian HR, Thakkar KH, Hamidi S, et al. A study of middle cranial fossa anatomy and anatomic variations. Ear Nose Throat J. 2007; 86(8): 474, 476-81, indexed in Pubmed: 17915670.

6. Erkoç MF, Ímamoglu H, Okur A, et al. Normative size evaluation of internal auditory canal with magnetic resonance imaging: review of 3786 patients Folia Morphol. 2012; 71(4): 217-220, indexed in Pubmed: 23197140.

7. Farahani R, Nooranipour M, Nikakhtar K. Anthropometry of Internal Acoustic Meatus. Int J Morphol. 2007; 25(4), doi: $10.4067 / \mathrm{s} 0717-95022007000400029$.

8. Fujita S, Sando I. Postnatal development of the vestibular aqueduct in relation to the internal auditory canal. Computer-aided three-dimensional reconstruction and measurement study. Ann Otol Rhinol Laryngol. 1994; 103(9): 719-722, doi: 10.1177/000348949410300910, indexed in Pubmed: 8085733.

9. Giesemann AM, Neuburger J, Lanfermann $\mathrm{H}$, et al. Aberrant course of the intracranial facial nerve in cases of atresia of the internal auditory canal (IAC). Neuroradiology. 2011; 53(9): 681-687, doi: 10.1007/s00234-011-0862-2, indexed in Pubmed: 21448638.

10. Huang BY, Roche JP, Buchman CA, et al. Brain stem and inner ear abnormalities in children with auditory neuropathy spectrum disorder and cochlear nerve deficiency. AJNR Am J Neuroradiol. 2010; 31(10): 1972-1979, doi: 10.3174/ ajnr.A2178, indexed in Pubmed: 20595372.

11. Ito K, Suzuki S, Murofushi T, et al. Neuro-otologic findings in unilateral isolated narrow internal auditory meatus. Otol Neurotol. 2005; 26(4): 767-772, indexed in Pubmed: 16015182.

12. Lang J. Clinical anatomy of the cerebellopontine angle and internal acoustic meatus. Adv Otorhinolaryngol. 1984; 34: 8-24, indexed in Pubmed: 6334984.

13. Li Y, Yang J, Liu J, et al. Restudy of malformations of the internal auditory meatus, cochlear nerve canal and cochlear nerve. Eur Arch Otorhinolaryngol. 2015; 272(7):
1587-1596, doi: 10.1007/s00405-014-2951-4, indexed in Pubmed: 24599597.

14. Marques SR, Smith RL, Isotani S, et al. Morphological analysis of the vestibular aqueduct by computerized tomography images. Eur J Radiol. 2007; 61(1): 79-83, doi: 10.1016/j.ejrad.2006.08.024, indexed in Pubmed: 17049195.

15. Marques SR, Ajzen S, D Ippolito G, et al. Morphometric analysis of the internal auditory canal by computed tomography imaging. Iran J Radiol. 2012; 9(2): 71-78, doi: 10.5812/iranjradiol.7849, indexed in Pubmed: 23329967.

16. Masuda S, Usui S, Matsunaga T. High prevalence of innerear and/or internal auditory canal malformations in children with unilateral sensorineural hearing loss. Int J Pediatr Otorhinolaryngol. 2013; 77(2): 228-232, doi: 10.1016/j. ijporl.2012.11.001, indexed in Pubmed: 23200870.

17. Polat C, Baykara M, Ergen B. Evaluation of internal auditory canal structures in tinnitus of unknown origin. Clin Exp Otorhinolaryngol. 2014; 7(3): 160-164, doi: 10.3342/ ceo.2014.7.3.160, indexed in Pubmed: 25177429.

18. Roche JP, Huang BY, Castillo $M$, et al. Imaging characteristics of children with auditory neuropathy spectrum disorder. Otol Neurotol. 2010; 31(5): 780-788, indexed in Pubmed: 20593543.

19. Rothschild MA, Wackym PA, Silvers AR, et al. Isolated primary unilateral stenosis of the internal auditory canal. Int J Pediatr Otorhinolaryngol. 1999; 50(3): 219-224, indexed in Pubmed: 10595667.

20. Rubinstein D, Sandberg EJ, Cajade-Law AG. Anatomy of the facial and vestibulocochlear nerves in the internal auditory canal. AJNR Am J Neuroradiol. 1996; 17(6): 1099-1105, indexed in Pubmed: 8791922.

21. Sennaroglu L, Saatci I. A new classification for cochleovestibular malformations. Laryngoscope. 2002; 112(12): 2230-2241, doi: 10.1097/00005537-200212000-00019, indexed in Pubmed: 12461346.

22. Sheth S, Branstetter BF, Escott EJ. Appearance of normal cranial nerves on steady-state free precession MR images. Radiographics. 2009; 29(4): 1045-1055, doi: 10.1148/ rg.294085743, indexed in Pubmed: 19605655.

23. Sildiroglu $O$, Cincik $H$, Sonmez $G$, et al. Evaluation of cochlear nerve size by magnetic resonance imaging in elderly patients with sensorineural hearing loss. Radiol Med. 2010; 115(3): 483-487, doi: 10.1007/s11547-0090440-4, indexed in Pubmed: 20039219.

24. Thomsen J, Reiter S, Borum $P$, et al. Tomography of the internal acoustic meatus. A critical evaluation of the radiological appearance in normals and in patients with acoustic neuromas. J Laryngol Otol. 1981; 95(12): 1191-1204, indexed in Pubmed: 7320615.

25. Verbist BM. Imaging of sensorineural hearing loss: a pattern-based approach to diseases of the inner ear and cerebellopontine angle. Insights Imaging. 2012; 3(2): 139-153, doi: 10.1007/s13244-011-0134-z, indexed in Pubmed: 22696040. 